Article

\title{
Response of Fresh Food Suppliers to Sustainable Supply Chain Management of Large European Retailers
}

\author{
Juan Carlos Pérez-Mesa ${ }^{1, *}$, Laura Piedra-Muñoz ${ }^{2} \mathbb{D}, \mathrm{M}^{\mathrm{a}}$ Carmen García-Barranco ${ }^{1}$ and \\ Cynthia Giagnocavo ${ }^{3}$
}

1 Agrifood Campus of International Excellence, ceiA3, Mediterranean Research Center on Economics and Sustainable Development, CIMEDES, Department of Economics and Business, University of Almería, 04120 Almería, Spain

2 Agrifood Campus of International Excellence, ceiA3, Mediterranean Research Center on Economics and Sustainable Development, CIMEDES, CEMyRI, Department of Economics and Business,

University of Almería, 04120 Almería, Spain

3 Agrifood Campus of International Excellence, ceiA3, Research Center on Intensive Mediterranean Agrosystems and Agrifood Biotechnology, CIAMBITAL, Department of Economics and Business, University of Almería, 04120 Almería, Spain

* Correspondence: juancarl@ual.es; Tel.: +34-950-21-41-02

Received: 17 June 2019; Accepted: 13 July 2019; Published: 17 July 2019

\begin{abstract}
This article analyses new supply chain management (SCM) strategies of the largest retail distribution chains in Europe within the context of differing sustainability concepts and approaches. An analysis is carried out of the strategic plans of such retailers, as well as recent developments in the sector. We begin by identifying the priority actions of retailers and then evaluating, by means of a survey, how small horticultural marketing firms (mainly cooperatives) in southeast Spain respond to the needs of these retailers. Subsequently, an analysis is carried out on these small marketing firm exporters to identify the relative weight which they assign to the variables assessed, while also considering the existing relationships between said weighted variables and business profits. Our results show that retailers tend to establish more simplified supply chains (that is, shorter and more vertical), essentially demonstrating their interpretation of a sustainable supply chain. In contrast, horticultural marketing firms have concentrated more on tactical and operational issues, thereby neglecting environmental, social and logistics management. Thus, their success rate in meeting the sustainability demands of their customers can be considered medium-low, requiring a more proactive attitude. Improved and collaborative relations, and the integration of sustainability concepts between suppliers (marketing firms) and their clients could contribute to successfully meeting sustainability demands. From the point of view of the consumer, close supplier-retail relationships have solved food safety issues, but the implementation of sustainability in other supply chain activities and processes is a pending issue. We propose strategic approximation and collaboration to bridge the gap between the varying sustainability demands in the supplier-retail relationship within perishable supply chains. Although this article specifically addresses fresh vegetable supply chains, the results may be extrapolated to other agri-food chains with a similar structure.
\end{abstract}

Keywords: international purchasing; sustainability; vegetable supply chain; marketing cooperatives

\section{Introduction}

The agricultural sector is currently under pressure to be sustainable and, at the same time, provide safe food to meet the demand of a growing world population. The efficient management of agri-food 
supply chains is a key concept for the agri-food sector's competitiveness, while also generating increasing interest among researchers and practitioners due to the growing demand for high quality, freshness (local), added value and customized agri-food products. It is important to highlight that the concept of a sustainable supply chain currently seems to encompass a wide range of possible aspects, on the one hand requiring actors to fulfill environmental and social criteria, while on the other hand expecting that competitiveness will be maintained by meeting customer needs and related economic criteria [1]. Emphasizing the environmental dimension, the literature suggests a new "green" or sustainable supply chain paradigm [2]. Including a social point of view, the sustainable supply chain paradigm is defined as a set of supply chain practices aimed at reducing environmental impact (measured in terms of carbon dioxide emissions, waste reduction, water consumption, etc.), as well as at improving the social condition of different stakeholders while contributing to the long-term economic development of the chain [3].

Numerous theoretical studies have attempted to determine what must be done to be both sustainable and competitive, yet few have analyzed the strategies that are actually applied in practice [4]. The present work seeks to fill this gap. From the practical point of view, the concept of sustainability within supply chains is quite broad, given that traditional strategies such as increasing flexibility, transparency, stock management, and so on may also affect environmental and social dimensions [5].

The distribution of agri-food products in Europe is currently undergoing a restructuring process, which affects retailers [6,7]. One of the most prominent changes is the growth of large-scale distribution. In contrast, more than half of the European farms specializing in horticulture measure less than two hectares, and they commercialize their products primarily through small-scale marketing cooperatives [8]. This restructuring implies drastic changes in supply chain processes [9], which affect the participation and collaboration of its participants [10-12]. In this context, suppliers are weak links that must find a way to adapt if they wish to survive when facing increasingly demanding customers with respect to product quality and safety, strict supply and environmental requirements, and low prices.

This article describes various supply chain management (SCM) strategies of retail distribution companies, focusing on the most prominent firms in Europe and on perishable products, specifically vegetables. Spain is the main European exporter of fruit and vegetables and its southeast region supplies around $64 \%$ of all horticultural exports. This specific area in southeast Spain comprises many small-scale suppliers (mainly cooperatives), whose production represent approximately $35 \%$ of all vegetables consumed in Europe in autumn-winter. In order to determine whether small-scale suppliers are able to provide sustainable, flexible, and efficient service to large-scale distributors, we analyze how the horticultural supply chain operates, beginning with the grower/seller in southeast Spain to its final destination in the supermarkets of other European countries.

The modern supply chain of horticultural products has well-defined phases that have been simplified in recent years (Figure 1) $[7,13]$. In the first phase, consideration should be given to the companies that sell horticultural supplies to growers, given the importance they have acquired in terms of marketing and their dominant presence (e.g., ChemChina, Syngenta and Bayer, and Montsanto). Moreover, seed and biotechnology companies increasingly design the final product with the end consumer in mind. The second phase of the supply chain is local trade, which involves cooperatives and auctions that receive products directly from growers and sell, for the most part, to purchasing groups and distributors (currently accounting for $70 \%$ of sales). Purchasing centers are companies run by distributors with the goal of concentrating and optimizing orders. Most large-scale retailers have main offices in Spain, such as Socomo (Carrefour), Edeka Fruchkontor, Zenalco (Auchan), Valencia Trading Office (Metro), Coop. Trading, among others.

Within this scenario, the grower/seller is an intermediate stakeholder with little influence due to the existence of a clear imbalance of negotiation power [14]. However, there is a lack of in-depth knowledge on these relationships and there are few recent studies that analyze strategies related to the SCM of large retail distributors in Europe. The present study aims to fill this gap in the literature 
by focusing on the existing relationships between large-scale distribution and small-scale fruit and vegetable suppliers in this case of southeast Spain. The goal is to study the challenges that these small suppliers must face in order to remain part of the supply chain. The results obtained contribute to the knowledge regarding some of the most critical issues that need to be addressed by the members of vegetable supply chains in order to be efficient and sustainable. In addition, they allow for the identification of future research areas.

The remainder of this paper is structured as follows: Section 2 presents a literature review of the peculiarities and tendencies of the perishable supply chain, the conceptual framework, and the hypothesis; Section 3 explains the proposed methodological framework; and the results and discussion are shown in Section 4. Finally, the main conclusions, some limitations, and future lines of research are summarized.

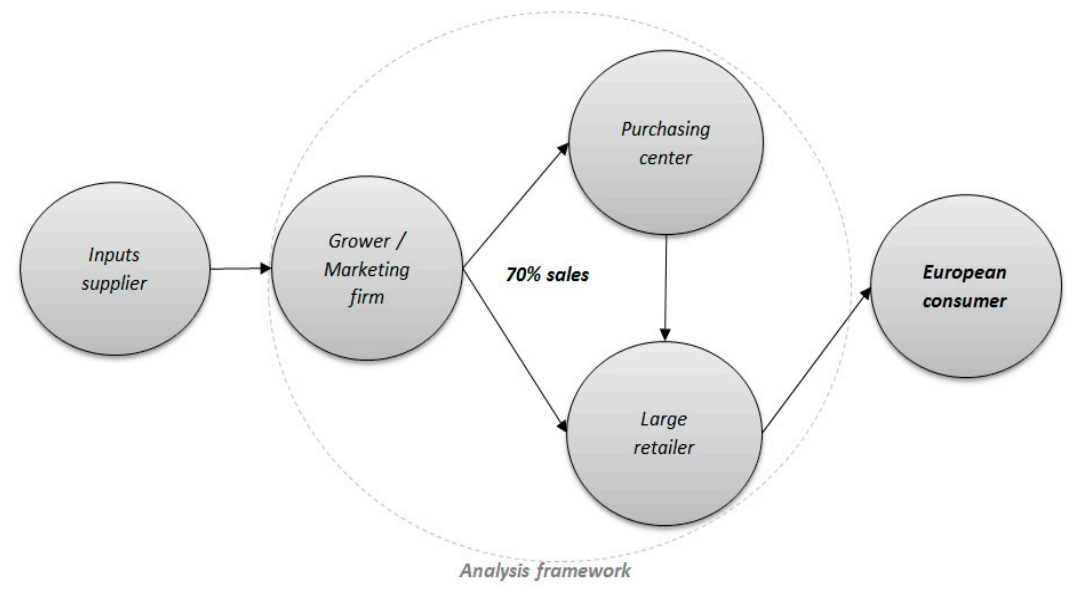

Figure 1. Modern horticultural supply chain summarized.

\section{Literature Review: Perishable Supply Chains}

The current supply chain structure is characterized by the variability of consumer demands, increased technology, and external socio-economic factors. This context requires closer relationships within supply chains and supply networks, which are understood as the series of operations necessary to produce and distribute products in correct quantities to chosen destinations in as little time as possible, all with the goal of satisfying the needs of the consumer [15]. This relationship is basically an inter-organizational network composed of multiple supplier-supplier-customer combinations, in which the improvement of an individual firm can only be achieved by optimizing the system as a whole [16]. One of the features of such a network is that one of the members, usually the retailer, exerts an influence over the remaining members; this is referred to as the "hub firm" [17]. In the specific case of agricultural products, the dominant firm is the retailer [18].

In terms of agricultural products, the chain must make maintaining quality and food safety standards of merchandise a top priority throughout the entire process from seed to fork [19]. With respect to perishables, consumers prefer products that are the freshest and have a reasonable price, which requires careful "fine-tuning" of SCM in terms of production planning and scheduling [13], in addition to coordination-collaboration-communication among companies [7,20]. Kumar et al. [21] found that coordination strategies are positively correlated with performance. In fact, the perishable supply chain is very complex due to the nature of the product, high uncertainty in demand and cost, and the increased consumer concern for food [22]. Thus, stakeholder cooperation is an important issue for optimal SCM performance [23]. In this sense, Manzini et al. [24] highlighted the interdependency of implications and decisions on food quality and environmental sustainability of supply chain processes and activities. This process is complicated even more so by the high number of intermediaries operating as fruit and vegetable brokers $[25,26]$. In this context, the fact that the products are perishable substantially reduces the time allowed for storage and transport processes [27], so much so that there is 
a general understanding that a certain amount of loss is inevitable [28]. One way to avoid this situation is to treat these products with special care along the supply chain, paying closer attention to certain aspects such as transport time, transportation systems (multimodality) [29], intermediary storage, and a reduction of handling processes [30], always taking into account the reduction of environmental footprint [31].

The complexity of resolving these issues, combined with the presence of consumers that are more concerned about sustainability and the environmental impact of the foods they buy [32,33], is prompting retail distribution to increase its use of short supply chains (SSCs). These chains are characterized by the existence of direct grower-consumer relationships, a reduced number of intermediaries, and minimized use of transportation. The incorporation of new digital business models supports this trend [34]. Such chains are made possible by the fact that products are grown in the same area in which they are consumed (proximity sales), which, in turn, fosters significant local social and economic benefits [35]. Short supply chains of proximity (SSCP) are normally associated with the sale of specific products that are not standardized. Recently, various studies have questioned the fact that this type of chain is linked to local development and the reduction of environmental impacts [36]. Viewed from another perspective, the term "short" might not refer to spatial proximity, but rather to keeping consumers completely informed about location and systems of production $[37,38]$. These chains are sometimes categorized as spatially extended (SSCE). In general, SSC may be seen as an approach to resolve problems that affect supply networks, particularly for the commercialization of European horticultural products. In addition, the consumer, in practice, identifies this type of chain with the concept of sustainability.

In sum, in the case of perishables, the relevant literature recognizes a series of both generic and specific trends that are closely related to each other, such as quality [39,40], uncertainty handling [41], health, SSC, CO2 footprint, and inter-modality [42], whose degrees of actual implementation in the chain are unknown.

\section{Conceptual Framework and Hypothesis}

Taking into account the particular characteristics mentioned above, six factors can be considered as playing a fundamental role in designing of a perishables supply chain [11]. These factors are (see Figure 2): (i) production scheduling [43,44], (ii) transportation [29,45,46], (iii) location of intermediate facilities [47,48]; and, transversally, (iv) guarantee of quality and food safety [49-51], (v) sustainability $[4,39,52]$, and (vi) coordination-collaboration-communication among actors, including the end customer [53-56]. It is important to note that quality and food safety are differentiated from other sustainability variables, primarily because these concepts are so vital to the agri-food chain that they become a separate entity (that is, they are a necessary condition). Retailers must establish their own policies regarding actions aimed at improving these variables, essentially urging their suppliers to adopt such practices. How quickly the latter adapts to this system is crucial for maintaining a satisfactory relationship for both parties $[39,57]$.

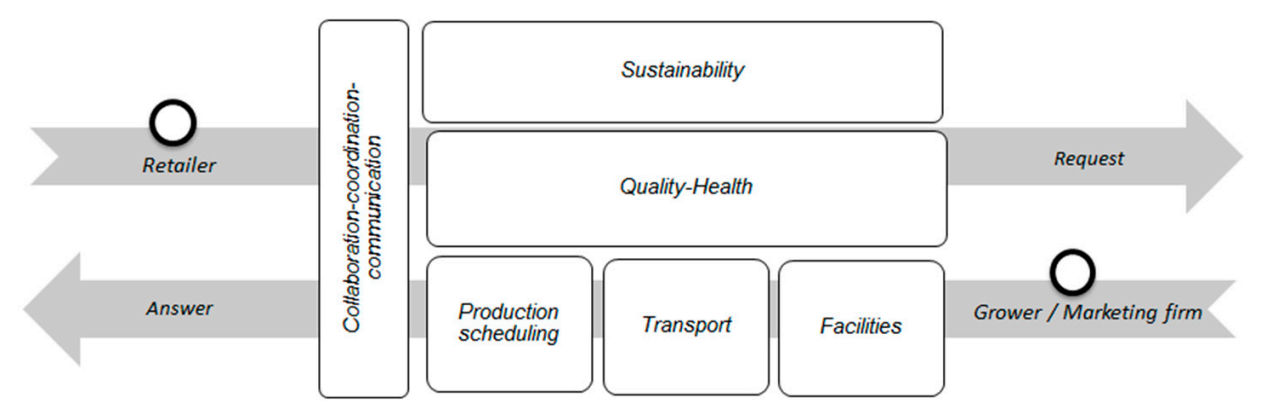

Figure 2. Conceptual framework. 
With this framework in mind, we may ascertain whether the small enterprise supplier of perishables is capable of satisfactorily responding to the requirements of their client (the retailer) with respect to the fundamental aspects that define the strategic plan of the supply chain. Diverse studies have analyzed the unequal relationships within perishable product supply chains, thus making supplier-client collaboration within the supply chain difficult $[8,10,11]$. As well, difficulties related to investment in conforming to protocols of quality, traceability, and other requirements that the customer considers indispensable are evident [27]. Subsequently, such research assumes as a point of departure the hypothesis:

Hypothesis 1 (H1). There is a gap between the priorities of the retailer and the response of the small supplier enterprises with respect to sustainability in supply chain management.

Other works emphasize the necessity for growth of the supplier in order to improve negotiation capacity and, in parallel, to increase functional efficiency $[7,13,18]$, which improves the competitiveness of the supply chain as a whole in the face of competition from other supply chains [58]. Therefore, the following sub-hypothesis is assumed:

Hypothesis 1a (H1a). Small supplier size and low efficiency can impede an agile response to the demands of supplier clients.

\section{Methodology}

\subsection{Retailer Requirements}

Based on the framework presented in Figure 2, the study was conducted as follows. First, research on trends in SCM was carried out for modern distribution in Spain (Mercadona, Carrefour, Dia, Auchan, and Eroski), France (E. Leclerc, Carrefour, Auchan Casino), Germany (Rewe, Edeka, Aldi, and Lidl), the United Kingdom (Tesco), and Poland (Tesco and Biedronka). The operations of the most important European retail chains were analyzed, which are essentially the products of their respective business plans. This work was accomplished by consulting: (1) documents related to their strategic plans (see [59], reports available for several years); and (2) news in specialized magazines and general media about the distribution sector (years 2013-2016). (The following magazines are notable for their specialization in the subject matter: Alimarket, FyH, Fruchthandel, and Mercados, as well as certain publications derived from important professional trades fairs, such as Fruitlogistica.) This information made it possible to identify the key actions that can affect horticultural suppliers located in the southeast of Spain. The necessity to follow tendencies and trends in sustainability reflected in media sources, due to their economic influence on the horticultural marketing firms in southern Spain, has been studied recently by Serrano et al. and Pérez-Mesa et al. [60,61]. Diverse methodologies can be employed to classify the information supplied by the media [62], and in this sense the present article carried out such classification in function of the aspects of veracity of the source/origin and pressure/specificity of the data supplied [63].

\subsection{Supplier Response}

In the second phase, it was considered important to determine whether suppliers are aware of the changes that are taking place in SCM (those changes made by their customers (i.e., big retailers)), and to what extent suppliers think they are able to respond to them. With this aim, and considering the key actions identified in the previous phase as well as the main factors of Figure 2, a survey was designed to ascertain the degree to which the main requirements of modern distribution have been fulfilled by suppliers. This survey was organized into five blocks (B) with three questions (R) per block, and answers based on a 7-point Likert scale, as is described below (see Appendix A, part 1). 
BI. Production Scheduling-Sustainability:

- $\quad \mathrm{R} 1=$ Customer collaboration in local-regional and social economic development.

- $\mathrm{R} 2=$ Production Scheduling with the customer in medium and long term.

- $\mathrm{R} 3=$ Customer collaboration in actions related to environmental impact of production.

BII. Production Scheduling-Quality:

- $\mathrm{R} 4=$ Implemented high rotation programs to promote quality (fresh produce sales, offers).

- $\quad \mathrm{R} 5=$ Degree of customer communication in relation to quality.

- $\mathrm{R} 6=$ Achieving quality requirements of customer.

BIII. Transport-Sustainability:

- $\quad$ R7 $=$ Use of intermodal transport as a sustainable transport mode.

- R8 $=$ Collaboration with customers to reduce transportation cost.

- $\mathrm{R} 9=$ Coordinating transport with customer in order to improve processes.

BIV. Transport-Quality:

- $\quad$ R10 = Collaboration with customer to select logistics providers according to quality service.

- $\quad \mathrm{R} 11=$ Selection of transport (groupage) depending on quality product.

- $\quad \mathrm{R} 12=$ Degree of quality control during transport.

BV. Facilities-Sustainability-Quality:

- R13 = Collaboration with customer for quality at destination (logistics blocks).

- $\mathrm{R} 14=$ Supply directly to store to reduce the environmental impact of routes.

- $\mathrm{R} 15=$ Using warehouse destinations for route optimization.

\subsubsection{Sample}

Regarding the sample, 43 surveys were obtained from a variety of companies: 63\% cooperatives, $18 \%$ fruit and vegetables exchanges, and $19 \%$ other exporting firms, with $82 \%$ of all companies located in a province called Almería. The horticultural exporting industry in southeast Spain comprises 230 companies, of which approximately 170 have their headquarters in Almería. Therefore, the response rate was roughly $20 \%$.

Additionally, the present study was able to obtain the sales figures (SAL), production results (PRO), and assets (ASS) for each of the companies consulted (annual averages 2013-2016). These data were obtained through the Andalusian Association of Agri-food Cooperatives and from the Iberian Balance Sheets Analysis.

\subsubsection{Weighting of the Importance of Supplier Responses}

The next phase consisted of assessing the weight given by operators to each of the variables tested to determine whether there was a relationship between the fulfillment of said variables and the relative importance that companies place on them. The survey (see Appendix A, part 2) was applied in accordance with Analytic Hierarchy Process (AHP) methodology and was conducted among horticultural exporters with the aim of discovering the relative importance that this group actually assigns to each of the variable attributes analyzed (R1 to R15). Following Saaty [64], attribute weighting $\left(w_{t}\right.$, where $t=$ the number of variables utilized; in this case 15) was obtained based on pairwise comparisons. Saaty proposes a scale from 1 to 9 (1 equivalent to a similar importance between both attributes, while 9 represents an absolute supremacy of the first attribute with respect to the second). In the present study, a matrix was generated for each respondent that compares the importance of each variable with each of those remaining (Tables 1 and A2). The advantages of AHP over other 
multi-criteria methods are its flexibility, intuitive appeal to the decision makers (experts here), and its ability to check the inconsistencies in judgments [65]. In our case, where opinions of several decision makers should be collected, AHP helped to elicit the complex judgements of different experts in a common platform. This ensured that the judgements were provided only with sufficient care and errors due to negligence were thus minimized.

Table 1. Saaty's matrix for each respondent.

\begin{tabular}{ccccc}
\hline Variables & $\mathbf{R 1}$ & $\mathbf{R} 2$ & $\ldots$ & $\mathbf{R} 15$ \\
\hline $\mathrm{R} 1$ & $\mathrm{a}_{1,1}=1$ & $\mathrm{a}_{1,2}=\left(1 / \mathrm{a}_{2,1}\right)$ & $\ldots$ & $\mathrm{a}_{1,15}=\left(1 / \mathrm{a}_{15,1}\right)$ \\
$\mathrm{R} 2$ & $\mathrm{a}_{2,1}$ & $\mathrm{a}_{22 \mathrm{k}}=1$ & $\ldots$ & $\mathrm{a}_{2,15}$ \\
$\ldots$ & & $\mathrm{a}_{15,2}$ & 1 & $\mathrm{a}_{15,1}=1$ \\
$\mathrm{R} 15$ & $\mathrm{a}_{15,1}$ & $\ldots$ & \\
\hline
\end{tabular}

With regard to the calculation of the specific weights each respondent assigned to the various attributes, the geometric average was chosen, mainly because the literature [66] identifies no one method as being absolutely superior to other systems. Thus, all the information provided by the respondents must be summarized (h). Moreover, although the AHP technique (applied in this study) was designed for individual decisions, it was later widely applied to group decisions [67]. Precisely as Forman and Peniwati [68] propose, the geometric mean was utilized, once again, to include the respondents:

$$
w_{t}=\left[\prod_{k=1}^{h} a_{i k}\right]^{1 / h}
$$

Given the complexity of conducting this type of survey, in which the respondent must make 105 comparisons, it was decided to apply the survey to a selected group of five people, namely, the representatives of the largest companies. (Thanks to the collaboration of the Association of Producers and Exporters of Fruit and Vegetables (COEXPHAL).)

\subsubsection{Relationship between Degree of Compliance, Size, and Performance}

Finally, a regression analysis was carried out to determine whether it can be empirically demonstrated that the various blocks evaluated by operators (weighted according to the relative importance) had some degree of measurable influence on the results. Based on the information obtained, the following dependent variables were defined to measure firm performance:

- $P R X_{i}=P R O_{i}-\overline{P R O}$ as an indicator of abnormal returns [69], where $P R O_{i}=$ pre-tax profits for company $\mathrm{i}$ and $\overline{P R O}=$ annual average profits. Several research works have adopted a similar approach regarding the use of explanatory variables of profitability in export companies (e.g., [70]).

- $P R X_{i} / S A L_{i}$ is an indicator of the effort required to achieve the result, where $S A L_{i}$ are the sales for company i. All these measures are indicators of the company's performance and have been used in previous research works [15,71].

The average scores per block $\left(B_{n}\right)$ that were obtained in the survey are introduced as independent variables. Said scores were weighted according to the importance they obtained in the pairwise comparison conducted using Saaty's method: $B^{\prime}{ }_{n i}=\sum_{n=1}^{5} B_{n i} \cdot w_{n i}$ where $\mathrm{i}=$ the number of observations and $\mathrm{n}=$ the number of blocks (in the present case 5).

The control variable used was $A S S_{i}=$ assets, serving as an indicator of dimension. The former was calculated in logarithms in order to be used as a proxy variable of the existence of internal scale economies [72]. Larger companies will have productive advantages that will make them more profitable. 


\section{Results Analysis and Discussion}

\subsection{Analysis of Retailer Strategies and Operations}

Regarding the strategies and operations management in large-scale distribution (summarized in the system represented in Figure 2), we can observe that there is a tendency towards creating partnerships with suppliers that strengthen enterprise planning by offering increased reliability in supplying products. As well, it is evident that it is quite common to establish contractual agreements, when possible, with nearby suppliers in order to develop the local economy, with a preference for direct delivery to shops and reducing stops at intermediate warehouses (SSCPs). This system is based on the creation of logistical collaboration platforms between the supplier and customer that are near retail establishments, focusing on regional distribution. The distribution sector is aware that even though there is a need to simplify logistical processes, the continuous search for new suppliers is crucial, regardless of location, as long as they have the capacity to maintain sustainability standards (SSCEs). Another key point is the use of intermodal transportation. Despite its inclusion in most strategic distribution plans, it still remains a medium-term objective, thus demonstrating how complicated its implementation is with respect to perishable products with high seasonality. There is, however, a growing interest in new technologies. In this respect, the aim is to improve and facilitate all communication activity among stakeholders in the supply chain. Initiatives also exist that focus on reducing environmental impact (carbon footprint), although no obligatory measurement has yet been insisted on by suppliers. In sum, this practice appears to be a first step towards reducing environmental impacts, including water usage. Table 2 below provides details on these strategies.

\subsection{Responses of Horticultural Exporters}

A preliminary analysis of the data (mean, standard deviations and correlation coefficients of variables) is detailed in Appendix B (Table A1). The most notable response is the significant individual relationship of variables R2 (production scheduling with the customer), R3 (customer collaboration in actions related to environmental impact of production) and R9 (coordinating transport with customer) with sales.

Cronbach's alpha is commonly used to provide information on the average correlation between elements. Thus, we apply it to measure how closely related each group of items (R) is as a block. It is recommended that the alpha value be greater than 0.6. Calculations of Cronbach's alpha per block revealed very low results $(<0.6)$ due to the use of a rather heterogeneous sample of companies, both in terms of their size and, therefore, in terms of their management system. Upon modifying the sample according to sales data, the alpha value improved considerably (all were above 0.84; the minimum value corresponding to BIII).

Figure 3 displays the initial data, and the simple average corresponding to each one of the variables analyzed can be observed. The results were then weighted according to sales and profits. The survey revealed that horticultural operators consider that they have made a great deal of effort in coordinating with customers in terms of production scheduling and quality management, as well as in meeting requirements imposed by the latter (variables $R 2, R 5$, R6, with a achievement rate of approximately $77 \%$; that is, 5.4 over 7 ). With regard to transportation, collaboration with customers to reduce costs was also a high-priority issue (variable R8, with a success rate of $75 \%$ ). The weighted average shows that aspects related to coordinated production scheduling with customers, the reduction of social and environmental impact, and the optimization of transport were given special priority among the largest firms (i.e., with the highest sales). In other words, high volume implies a need to fine-tune the coordination of production and transport activities, in addition to taking into account any impacts that production may have on the local area. 
Table 2. Supply chain management (SCM) strategic trends in large-scale distribution in Europe.

\begin{tabular}{|c|c|c|}
\hline \multicolumn{3}{|c|}{ Coordination-Collaboration-Communication } \\
\hline & Sustainability & Quality-Food Safety \\
\hline \multirow{16}{*}{ Production scheduling } & \multicolumn{2}{|l|}{ Development of local economies: } \\
\hline & \multirow{7}{*}{$\begin{array}{l}\text { Mercadona, Carrefour, Eroski, Día, Aldi, Grupo Emperia, through local } \\
\text { supplier strategy. } \\
\text { Incorporation of environmentally responsible solutions: } \\
\text { - Eroski and Aldi utilize returnable containers. } \\
\text { - Carrefour demands ISO } 14001 \text { certifications from suppliers. } \\
\text { Recycling merchandise: } \\
\text { - Carrefour converts its store waste into biofuel. } \\
\text { Fair trade: }\end{array}$} & Promote sales of fresh products: \\
\hline & & - Mercadona promotes individual store management policies \\
\hline & & to favor stock rotation. \\
\hline & & Daily quality control at points of sale: \\
\hline & & - Priority strategy for Eroski and Tesco. \\
\hline & & Direct supplier-customer relationships: \\
\hline & & - Tesco ensures quality control of its products by \\
\hline & $\begin{array}{l}\text { - Auchan works with a specific line of products. } \\
\text { - Biedronka selects suppliers based on strict controls, respect for ethical } \\
\text { practices, and possession of certifications. }\end{array}$ & $\begin{array}{l}\text { Control product origin: } \\
\text { - Tesco obtains products from various regions and countries } \\
\text { to ensure product availability. }\end{array}$ \\
\hline & Total management of supply chain: & Commitment to traceability: \\
\hline & \multirow{4}{*}{$\begin{array}{l}\text { Mercadona fixes long-term prices agreed upon with suppliers. In general, } \\
\text { the firm utilizes the inter-supplier model to maintain more direct } \\
\text { collaboration with its suppliers. } \\
\text { Carrefour schedules its inventories in medium and long term, thereby } \\
\text { simplifying the functioning of the chain and reducing response time } \\
\text { through the exchange of information among all stakeholders involved. }\end{array}$} & - All chains. \\
\hline & & Strict demands for quality certifications and standards: \\
\hline & & - All chains \\
\hline & & Considerable growth of organic product sales: \\
\hline & \\
\hline & $\begin{array}{l}\text { - Tesco and Mercadona seek to establish long-term relationships with local } \\
\text { growers and manage products directly from farms. }\end{array}$ & \\
\hline
\end{tabular}


Table 2. Cont

\begin{tabular}{|c|c|c|}
\hline & \multicolumn{2}{|c|}{ Coordination-Collaboration-Communication } \\
\hline & Sustainability & Quality-Food Safety \\
\hline Transportation & $\begin{array}{l}\text { Use of intermodal transportation: } \\
\text { - Grupo Casino uses maritime transport to supply points of sale. } \\
\text { - Tesco promotes the use of railway and maritime transport to supply } \\
\text { intermediate facilities. } \\
\text { Grupo Schwarz utilizes railway and shipping containers (international } \\
\text { ports, such as Rotterdam). } \\
\text { - } \quad \text { Aldi uses maritime transport to supply its distribution centers. } \\
\text { - Carrefour promotes the use of railway and maritime transport. } \\
\text { Optimized transportation of merchandise: } \\
\text { - Eroski uses additives in the fuel of its vehicles to reduce } \mathrm{CO}_{2} \text { emissions. } \\
\text { - } \quad \text { Día promotes the use of dual fuel trucks (diesel + biofuel). } \\
\text { - Carrefour uses trucks that pollute less, and is starting to experiment with } \\
\text { - hybrid and electric vehicles. } \\
\text { - Carrefour promotes maximizing means of transport, including completely } \\
\text { full trucks and carrying merchandise from various suppliers. } \\
\text { Grupo Casino and Tesco include reduction of environmental impact of } \\
\text { transportation in their strategic plans. } \\
\text { Externalization of transportation costs: } \\
\text { - Suppliers of Aldi and Tesco assume transportation costs. } \\
\text { Products directly from supplier to point of sale: } \\
\text { - } 5 \% \text { of Aldi merchandise is brought directly to shops from } \\
\text { - Tesco intends to eliminate intermediaries through implementation of } \\
\text { direct sourcing. } \\
\text { - Auchan uses the previous strategy with certain products. } \\
\text { - Similar strategies for other distributors: Mercadona, Carrefour, Grupo Les } \\
\text { Mousquetaires, Grupo Casino, Biedronka. }\end{array}$ & $\begin{array}{l}\text { Quality control of logistics providers: } \\
\text { - Eroski. } \\
\text { Unbroken cold chain: } \\
\text { - Rewe has vehicles equipped to transport various types of } \\
\text { products that feature three separate } \\
\text { climate-controlled compartments. } \\
\text { Transport differentiated by product type: } \\
\text { - Auchan. } \\
\text { Subcontracting of specialized logistics providers: } \\
\text { - Carrefour, Eroski, Auchan, Grupo Schwarz. }\end{array}$ \\
\hline
\end{tabular}


Table 2. Cont.

\begin{tabular}{|c|c|c|}
\hline & \multicolumn{2}{|c|}{ Coordination-Collaboration-Communication } \\
\hline & Sustainability & Quality-Food Safety \\
\hline Facilities & $\begin{array}{l}\text { Creation of supplier-customer distribution hubs: } \\
\text { - Carrefour intends to group intermediate distribution centers, aiming to } \\
\text { reduce its carbon footprint. } \\
\text { Local trade: } \\
\text { - Carrefour. } \\
\text { Facility locations near transport: } \\
\text { - Aldi locates its centers near Rotterdam port to favor international trade. } \\
\text { Logistics blocks located close to market: } \\
\text { - Mercadona, Auchan, Rewe, and Lidl possess supply centers near points } \\
\text { of sale. } \\
\text { Aldi conducts a regional supply system with the maximum distance from a } \\
\text { Interistics center to point of sale being } 50 \text { km. } \\
\text { - Rewe also invests in centers near intermediate supply areas such as } \\
\text { wholesale markets (Hamburg). } \\
\text { Edeka supplies its regional platforms from the central group. } \\
\text { - Leckerc has regional supply centers. } \\
\text { - Ahold center is located close to the main Czech wholesale market (Prague). } \\
\text { - Biedronka concentrates its points of sale near supply centers. } \\
\text { Logistics platforms at destination: } \\
\text { Edeka has purchase platforms located in its suppliers' countries. }\end{array}$ & $\begin{array}{l}\text { Product control at logistics centers: } \\
\text { Eroski has implemented procedures to guarantee product } \\
\text { quality within its logistics blocks. }\end{array}$ \\
\hline
\end{tabular}




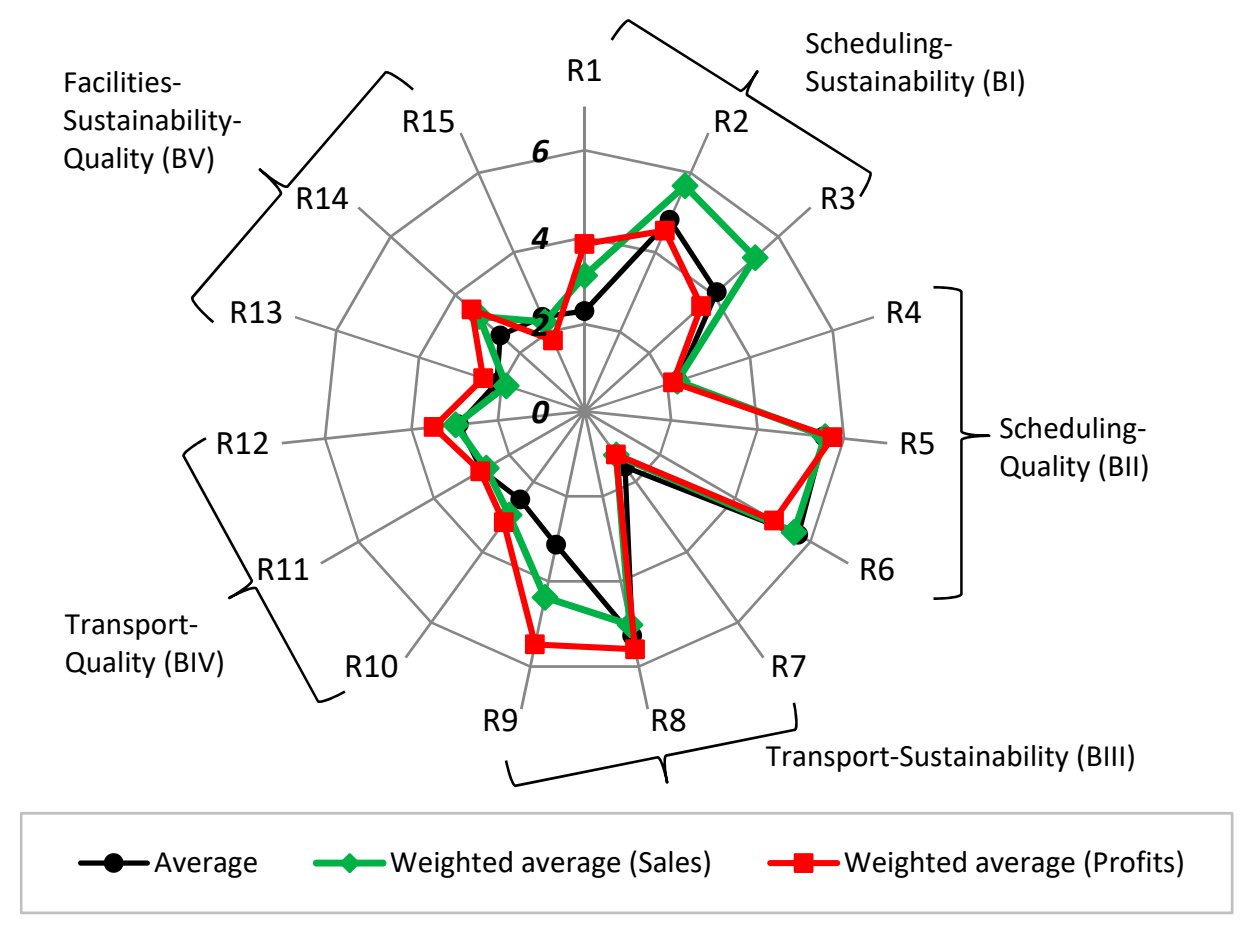

Figure 3. Survey results. Success rate (1-7).

Each block accurately presents the following results:

- BI. Marketing enterprises respond well when scheduling their production according to what customers order (R2), as well as in terms of matters related to environmental and social impact (R3). They do not collaborate with the customer in local economic development (R1).

- BII. As for quality issues, there is a close relationship with the customer (R5), accepting the latter's requests (R6). It is necessary to increase production programs of high rotation to promote quality (R4).

- BIII. There is no collaboration to implement inter-modality (R7), but there is to reduce costs of transport and other processes (R8, R9).

- BIV. Results obtained are low regarding collaboration with the customer to improve transport quality.

- BV. In addition, little has been done in terms of collaboration to optimize deliveries and intermediate facilities.

By grouping the various aspects into blocks (Figure 4), it becomes quite clear that suppliers have concentrated their efforts on aspects related to production scheduling to increase quality and sustainability. Success was lower in terms of objectives related to improving transport and location to favor logistics. In any case, it can be seen that there exists considerable room for improvement-the best blocks displayed a success rate of about $60 \%$ (4.1 over 7$)$; with moderate effort, they could fully achieve their objectives. 


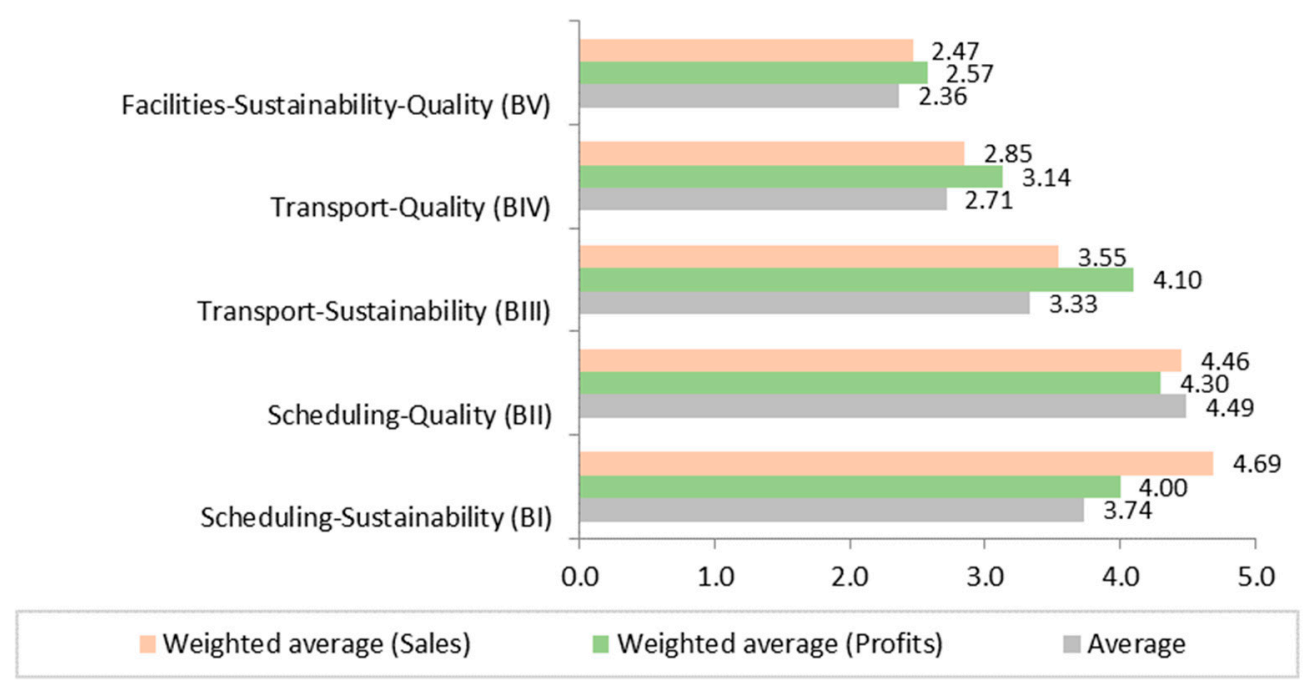

Figure 4. Survey results. Success rate by block (1-7).

Figure 5 displays the results of the AHP analysis, which was conducted on horticultural exporter enterprises with the objective of determining the relative importance of the different variables (see Saaty's average matrix in Appendix C, Table A2). The results reveal total correspondence between relative importance and success rate; that is, the companies themselves work to achieve the objectives that they themselves consider most important. Once again, it is observed that variables R2 (production scheduling with the customer), R5 (degree of customer relationships in quality), and R6 (meeting quality requirements imposed by the customer) are the most important, combining to total $38 \%$. By grouping into blocks (Figure 6), it is also observed, as expected, that production scheduling conducted with the goal of improving quality (BII) is considered a priority. It should be noted that this block registered a $64 \%$ success rate (Figure 4 ); that is, 4.49 over 7 .

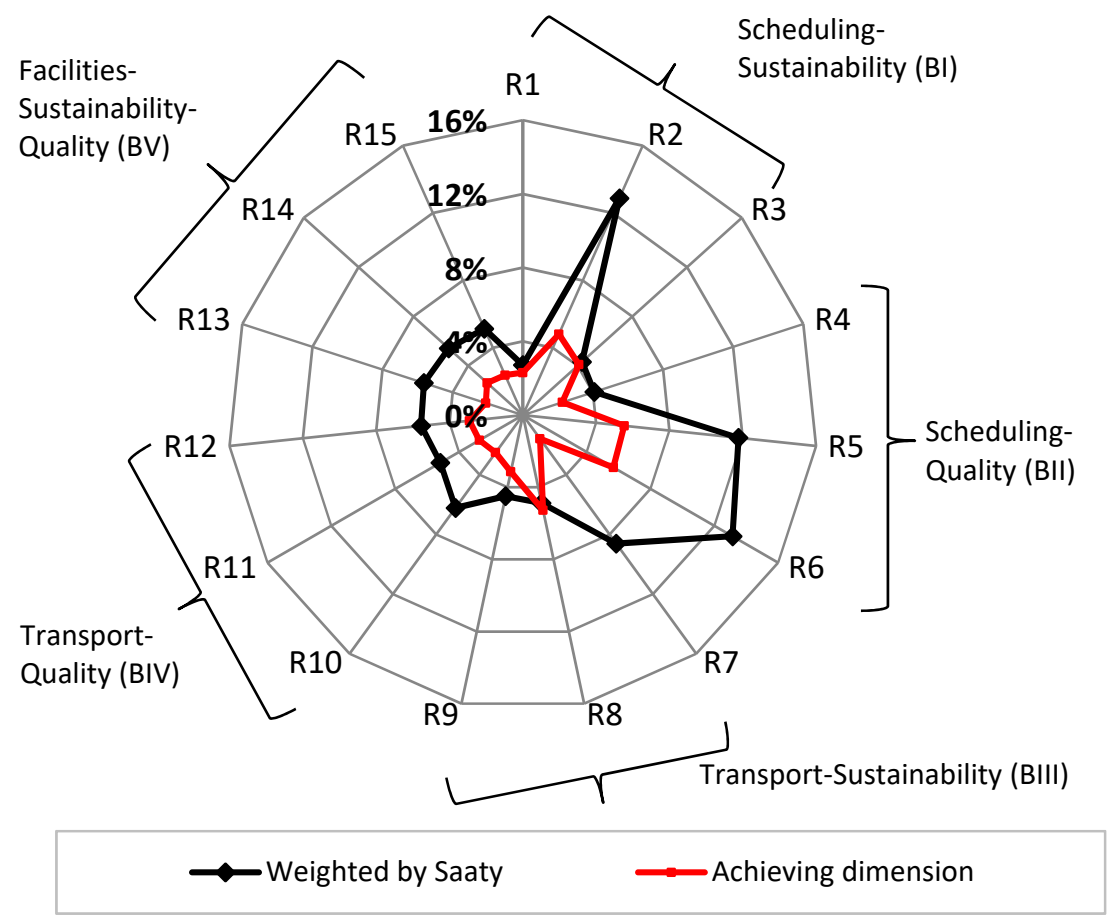

Figure 5. Results of weighting variables according to their influence and success rate. Success rate = values from 1-10. Introduced to facilitate comparison. 


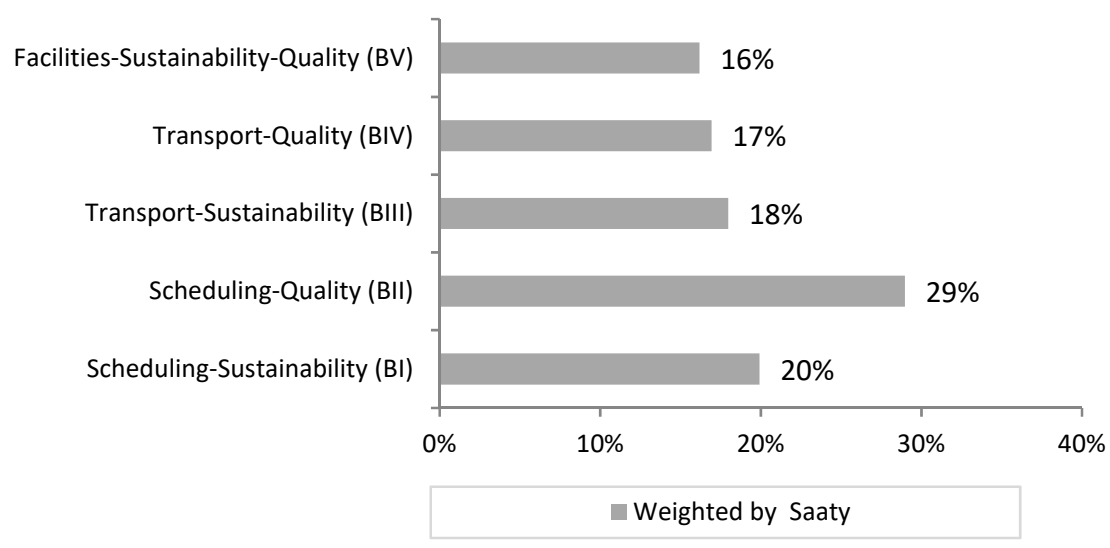

Figure 6. Results of weighting blocks according to their influence.

Finally, a regression analysis was carried out to show the relationship existing between the various blocks evaluated by marketing enterprises (weighted according to relative importance) and business profits. The results obtained from the model utilized can be seen in Table 3, where it can be observed that the only block that has a significant influence on the results is $B^{\prime}{ }_{I I}$, which represents the effect of efforts regarding production scheduling and quality. This fact is consistent with the marketing enterprises' perception that this specific block is the most important with respect to obtaining profits. However, the fact that the remaining blocks are non-significant might owe to the low success rate in fulfilling the aspects that comprise the blocks themselves (specifically BIII, BIV, and BV).

Table 3. Relationships between weighted blocks and business profits.

\begin{tabular}{ccc}
\hline Variables & Profits & Profits/Sales \\
\hline Constant & 80.208 & -11.859 \\
Production Scheduling-Sustainability $\left(B^{\prime}{ }_{I}\right)$ & 4.276 & 2.336 \\
Production Scheduling-Quality $\left(B^{\prime}{ }_{I I}\right)$ & $* * 19.100$ & $* 3.985$ \\
Transport-Sustainability $\left(B^{\prime}{ }_{I I I}\right)$ & 2.385 & 0.557 \\
Transport Quality $\left({B^{\prime}}{ }_{I V}\right)$ & 8.020 & 1.386 \\
Facilities-Sustainability-Quality $\left(B^{\prime}{ }_{V}\right)$ & 7.902 & 2.079 \\
Assets & $* 8.081$ & $* 2.610$ \\
\hline F-stat & $* * * 4.662$ & $* * * 3.978$ \\
$\mathrm{R}^{2}$ Adjusted & 0.343 & 0.310 \\
$\chi^{2}$ Farrar-Glauber & 6.240 & 8.340 \\
White Test & 8.121 & 9.339 \\
\hline (*** &
\end{tabular}

\subsection{Discussion}

Large retailers are reconsidering all their supply chain processes and attempting to internalize some of them as a way of distinguishing themselves from their competition, as well as a means of reducing costs. Examples of this trend include: closer relationships with growers (as in [37,38]); establishment of medium-term agreements to achieve price stability; implementation of their own quality protocol (with a tendency towards total sustainability) [19,49,50]; and internal management of logistics by means of local purchasing centers. In parallel, the simplification of operations is another key element in distribution, as it is also shown in previous studies [7,13]. In fact, this is quite frequently the goal in mind when carrying out internalization of activities [11].

Regarding the actions of small marketing enterprises, they have focused on responding to the most tactical and operational issues, pushing many long-term problems to the side. On the whole, marketing enterprises believe they possess good production scheduling in terms of quality (regarding food safety), in the short, medium, and long terms. These aspects are considered as priorities. However, 
social and environmental management of production have been relegated to secondary status, despite being key aspects for establishing SSCE, particularly considering that consumers want to know that their purchases generate positive environments and social externalities. Transport, in the majority of cases, is managed by the customer. In general, local companies have overlooked aspects related to logistics management, which include establishing intermediate facilities. Relationships with customers in terms of these aspects are very limited, as in $[7,13,18]$. In sum, the success rate in fulfilling customer demands by horticultural marketing enterprises in southeast Spain can be categorized as medium-low.

An important point to consider is that the most profitable and largest companies are the most well-balanced in all aspects of sustainable SCM. This result is in accordance with those found in [66]. This finding may conflict with the trend in large-scale distribution to eliminate dealings with local intermediaries (e.g., marketing cooperatives). However, these enterprises, contrary to what retailers appear to think, would allow large-scale distribution to further establish its sustainability objectives.

The relationship between short-term quality management and company profitability is tacitly recognized in the sector and, at the same time, is shown to exist. This finding is similar to those of previous studies, e.g., [73]. This connection leads suppliers to concentrate their efforts on short-term quality management, inadvertently neglecting, as mentioned earlier, other, arguably more important, strategic challenges.

In general, the results corroborate the point of departure hypotheses. A gap exists between the priorities of the retailer and the response of small supplier enterprises, predominantly marketing cooperatives (H1). The supply enterprises should focus their efforts on improving environment management (e.g., boosting the circular economy [74]), as well as the social dimension, through greater involvement in solving local problems, such as the insertion of immigrant labor [61].

With respect to (H1a), the most profitable enterprises and those which are of larger sizes are able to better respond to the needs of their clients. In this sense, retailers should promote agreements with companies, thus rethinking their strategy of direct purchase from the horticultural producer (grower). Organizing production and sales around social economy enterprises adds value to the sustainable supply chain [75].

\section{Conclusions}

This work has centered on the disequilibrium of the relations between small supplier enterprises and retailers, and the difficulties of strategic management in perishable supply chains. As a new contribution, this article has analyzed the capacity of small suppliers of perishable vegetables to satisfactorily respond to the demands of their clients (retailers) with respect to the fundamental aspects that define the strategic planning of sustainable supply chains. We have shown the diversity in the approaches taken to sustainability, as well as demonstrating the potential role of collaboration.

The fruit and vegetable suppliers of European retail distribution chains must respond to their customers' requirements if they wish to maintain their position. At present, the demands made on such suppliers are increasing. This trend is visible in the rigorous audits that companies conduct on suppliers prior to signing business agreements, which are typically followed by periodic inspections. In addition, the supplier-customer relationship is undergoing changes. Retailers tend to establish supply chains that are shorter and more vertical (SSCE-type), eliminating not only intermediaries and brokers, but even local marketing firms (cooperatives), with the aim of dealing with growers directly. There is also a growing trend towards SSCP given its high acceptance rate among consumers, although these are still currently a minority. It should be noted that, among consumers, there is a growing recognition of SSCs as sustainable chains. In sum, retailers are aware of the importance of a sustainable chain, yet they also understand the difficulty of implementing such a system, both for them and their suppliers. Indeed, they are "translating" the concept into direct sales and the simplification of processes, without directly addressing the issue.

On the other hand, the suppliers, the majority being cooperatives or social enterprise entities of small sizes, have problems in responding to their clients. They have had to concentrate their 
efforts in operational problems, centered on food safely, leaving aside those strategic aspects related to environmental and social sustainability. In this framework, the attitude of the retailer is contradictory, because it favors the atomization of its suppliers, when on the contrary it has been shown that large enterprises can better respond to their demands for sustainability.

From the point of view of practical implications, this context requires a more proactive attitude by suppliers. Furthermore, it is necessary to have properly qualified and dedicated human capital to know, understand, and manage what is required by customers. In parallel, the retailer should be involved in improving the competitivity of its suppliers through collaboration, not simply limiting themselves to imposing requirements without providing or supporting the means to implement such demands. The gap between customer demands and supplier response may increase in the future if mutual collaboration links in the chain are not improved. Changes made locally should not be imposed by customers, which is precisely the current situation, and retailers might be jeopardizing their entire supply as local firms do not appear to be prepared to respond in the medium and long terms. The sharing of strategic information between retailers and suppliers, so as to improve integration, may be a first stop to close the gap, given that it would free up the resources of suppliers who could then dedicate themselves to improving other processes. In general, retailers should select their suppliers and initiate a much more stable relationship.

Although the results obtained may be of interest to other similar agri-food supply chains, this work has several limitations that could serve as references for future research. For example, since the present work focused on the largest retail distribution chains in Europe, a comparison with other international supply chains could be of interest (that is to say, to determine if such strategies are geographically stable). Additionally, future work could focus on expanding the strategies and variables considered and also determining their evolution over time. As well, the sample of products could be expanded beyond perishables to determine the strategic differences, both for the retailer and supplier, given that the product could have an influence on SCM. Finally, the role of technology and ICT in enhancing collaboration in sustainable SCM should be explored.

Author Contributions: All authors contributed to the analysis of the data and to the writing of the manuscript. All authors read and approved the final manuscript.

Funding: This research was partially funded by Spanish MCINN and FEDER aid (project ECO2017-82347-P), and the European Commission (EMME project, AMIF/2017/AG/INTE/821726, and IoF2020 project no. 731884 and NEFERTITI project No. 772705).

Conflicts of Interest: The authors declare no conflict of interest.

\section{Appendix A. Survey}

\section{PART1}

The following survey will take five minutes. The information you provide will help us understand the functioning of the Fruit and Vegetable Supply Chain in southeastern Spain. This is an anonymous questionnaire, in which the answers will be strictly confidential. We appreciate your sincerity.

Corporate control data (average of the last three years):

- Turnover (euros):

- Profit Before Taxes (euros):

- Business Assets (euros):

You will then have to assess from 1 to 7 the degree of compliance with the different questions put to you. 


\section{Production-Sustainability Programming}

1. Do you collaborate with your client in the development of the local economy of your region?

\begin{tabular}{|l|l|l|l|l|l|l|}
\hline 1 & 2 & 3 & 4 & 5 & 6 & 7 \\
\hline & & & & & & \\
\hline
\end{tabular}

2. Do you carry out a medium or long term sales program with your client?

\begin{tabular}{|l|l|l|l|l|l|l|}
\hline 1 & 2 & 3 & 4 & 5 & 6 & 7 \\
\hline & & & & & & \\
\hline
\end{tabular}

3. Do you carry out actions aimed at controlling the social and environmental responsibility of your production?

\begin{tabular}{|l|l|l|l|l|l|l|}
\hline 1 & 2 & 3 & 4 & 5 & 6 & 7 \\
\hline & & & & & & \\
\hline
\end{tabular}

\section{Production-Quality-Health Programming}

4. Do you have a sales program where the customer demands a continuous supply (high rotation) with the aim of promoting the freshness of the product at the point of sale?

\begin{tabular}{|l|l|l|l|l|l|l|}
\hline 1 & 2 & 3 & 4 & 5 & 6 & 7 \\
\hline & & & & & & \\
\hline
\end{tabular}

5. Are the relationships with your supplier in terms of quality-healthiness continuous and close?

\begin{tabular}{|l|l|l|l|l|l|l|}
\hline 1 & 2 & 3 & 4 & 5 & 6 & 7 \\
\hline & & & & & & \\
\hline
\end{tabular}

6. Do you always meet your customer's quality certification requirements?

\begin{tabular}{|l|l|l|l|l|l|l|}
\hline 1 & 2 & 3 & 4 & 5 & 6 & 7 \\
\hline & & & & & & \\
\hline
\end{tabular}

\section{Transport-Sustainability}

7. Do you use intermodality in freight transport?

\begin{tabular}{|l|l|l|l|l|l|l|}
\hline 1 & 2 & 3 & 4 & 5 & 6 & 7 \\
\hline & & & & & & \\
\hline
\end{tabular}

8. Do you use collaboration strategies with your client so that the economic and environmental costs in the transport of goods are lower?

\begin{tabular}{|l|l|l|l|l|l|l|}
\hline 1 & 2 & 3 & 4 & 5 & 6 & 7 \\
\hline & & & & & & \\
\hline
\end{tabular}

9. Does your client assume the cost of transport with the aim of optimizing routes?

\begin{tabular}{|l|l|l|l|l|l|l|}
\hline 1 & 2 & 3 & 4 & 5 & 6 & 7 \\
\hline & & & & & & \\
\hline
\end{tabular}

\section{Transport-Quality-Health}

10. Do you coordinate with your client the hiring of logistic suppliers in order to assure the quality of the service?

\begin{tabular}{|l|l|l|l|l|l|l|}
\hline 1 & 2 & 3 & 4 & 5 & 6 & 7 \\
\hline & & & & & & \\
\hline
\end{tabular}


11. Do you carry out any type of discrimination in the transport (groupage) depending on the product or destination of the production due to the demands of your client?

\begin{tabular}{|l|l|l|l|l|l|l|}
\hline 1 & 2 & 3 & 4 & 5 & 6 & 7 \\
\hline & & & & & & \\
\hline
\end{tabular}

12. Do you have any type of system to control the quality of the product in the transport?

\begin{tabular}{|l|l|l|l|l|l|l|}
\hline 1 & 2 & 3 & 4 & 5 & 6 & 7 \\
\hline & & & & & & \\
\hline
\end{tabular}

\section{Installations-Sustainability/Quality-Sanitation}

13. Do you collaborate with your client in maintaining the quality of the product in its logistics blocks?

\begin{tabular}{|l|l|l|l|l|l|l|}
\hline 1 & 2 & 3 & 4 & 5 & 6 & 7 \\
\hline & & & & & & \\
\hline
\end{tabular}

14. Do you supply your customers at the final point of sale?

\begin{tabular}{|l|l|l|l|l|l|l|}
\hline 1 & 2 & 3 & 4 & 5 & 6 & 7 \\
\hline & & & & & & \\
\hline
\end{tabular}

15. Do you use distribution warehouses in the main destinations to which you send your merchandise?

\begin{tabular}{|l|l|l|l|l|l|l|}
\hline 1 & 2 & 3 & 4 & 5 & 6 & 7 \\
\hline & & & & & & \\
\hline
\end{tabular}

\section{PART 2. WEIGHTING}

Weighing according to the importance of the implementation (economic outcomes/cost).

\begin{tabular}{|c|c|c|c|c|c|c|c|c|c|c|c|c|c|c|}
\hline & 2 & 3 & 4 & 5 & 6 & 7 & 8 & 9 & 10 & 11 & 12 & 13 & 14 & 15 \\
\hline 1 & & & & & & & & & & & & & & \\
\hline 2 & & & & & & & & & & & & & & \\
\hline 3 & & & & & & & & & & & & & & \\
\hline 4 & & & & & & & & & & & & & & \\
\hline 5 & & & & & & & & & & & & & & \\
\hline 6 & & & & & & & & & & & & & & \\
\hline 7 & & & & & & & & & & & & & & \\
\hline 8 & & & & & & & & & & & & & & \\
\hline 9 & & & & & & & & & & & & & & \\
\hline 10 & & & & & & & & & & & & & & \\
\hline 11 & & & & & & & & & & & & & & \\
\hline 12 & & & & & & & & & & & & & & \\
\hline 13 & & & & & & & & & & & & & & \\
\hline 14 & & & & & & & & & & & & & & \\
\hline
\end{tabular}

- $1=$ The importance of the variables is equal.

- $3=$ The row variable is slightly more important than the column variable.

- $5=$ The row variable is more important than the column variable.

- $7=$ The row variable is much more important than the column variable.

- $9=$ The row variable is extremely more important than the column variable.

- $1 / 3=$ The variable column is slightly more important than the variable row.

- $1 / 5=$ The variable column is more important than the variable row.

- $1 / 7=$ The variable column is much more important than the variable row.

- $1 / 9=$ The variable column is extremely more important than the variable row. 


\section{Appendix B}

Table A1. Descriptive statistics and pairwise correlation coefficients of variables.

\begin{tabular}{|c|c|c|c|c|c|c|c|c|c|c|c|c|c|c|c|c|c|c|c|}
\hline Variable & Mean & Dev. & PRO & ASS & R1 & R2 & R3 & R4 & R5 & R6 & R7 & R8 & R9 & R10 & R11 & R12 & R13 & R14 & R15 \\
\hline SAL & 36.001 & 50.14 & $0.321 *$ & $0.690^{* *}$ & $0.490^{* *}$ & $0.630^{* *}$ & $0.520^{* *}$ & -0.010 & -0.218 & -0.112 & $-0.357^{* *}$ & -0.167 & $0.641^{* *}$ & $0.365^{* *}$ & -0.075 & 0.059 & -0.225 & $0.422 * *$ & -0.097 \\
\hline PRO & 344 & 1.487 & & 0.226 & 0.098 & $0.326^{*}$ & -0.068 & -0.025 & 0.021 & $0.351^{* *}$ & 0.120 & 0.065 & $0.381^{* *}$ & 0.173 & 0.010 & 0.141 & 0.108 & 0.185 & 0.148 \\
\hline ASS & 15.792 & 23.604 & & & 0.402 ** & 0.630 ** & $0.495^{\text {** }}$ & -0.019 & -0.259 * & -0.066 & $-0.320 *$ & -0.169 & 0.587 ** & $0.326 *$ & -0.135 & 0.057 & $-0.305 *$ & $0.399 * *$ & -0.008 \\
\hline $\mathrm{R} 1$ & 2.302 & 1.225 & & & & $0.386^{* *}$ & 0.136 & $0.647^{* *}$ & 0.099 & 0.149 & -0.099 & 0.092 & 0.237 & 0.074 & -0.191 & 0.164 & 0.040 & $0.481^{* *}$ & -0.078 \\
\hline R2 & 5.233 & 2.114 & & & & & $0.263 *$ & 0.173 & 0.007 & 0.212 & -0.142 & -0.057 & $0.435^{* *}$ & 0.126 & 0.179 & -0.105 & -0.080 & $0.346^{*}$ & 0.003 \\
\hline R3 & 4.140 & 1.740 & & & & & & -0.032 & -0.077 & -0.074 & -0.206 & -0.068 & 0.152 & 0.247 & -0.004 & -0.006 & $-0.313^{*}$ & $0.269 *$ & 0.040 \\
\hline R4 & 2.256 & 1.071 & & & & & & & 0.238 & 0.139 & 0.147 & 0.194 & -0.084 & -0.368 ** & 0.001 & 0.001 & 0.204 & 0.144 & 0.161 \\
\hline R5 & 6.512 & 1.437 & & & & & & & & $0.454^{* *}$ & 0.361 ** & 0.187 & $-0.351 *$ & -0.211 & $0.411^{* *}$ & 0.069 & 0.146 & 0.068 & 0.293 * \\
\hline R6 & 6.395 & 1.545 & & & & & & & & & 0.047 & 0.125 & -0.222 & -0.047 & $0.303 *$ & 0.025 & -0.042 & 0.213 & 0.027 \\
\hline R7 & 1.581 & 0.698 & & & & & & & & & & 0.210 & $-0.353 *$ & $-0.262 *$ & 0.193 & -0.059 & 0.331 * & -0.124 & 0.240 \\
\hline R8 & 5.279 & 1.141 & & & & & & & & & & & 0.049 & -0.027 & -0.033 & -0.040 & 0.074 & 0.142 & -0.142 \\
\hline R9 & 3.186 & 1.607 & & & & & & & & & & & & $0.485^{* *}$ & -0.025 & 0.164 & -0.120 & 0.250 & -0.155 \\
\hline R10 & 2.512 & 0.883 & & & & & & & & & & & & & -0.176 & 0.390 ** & -0.242 & 0.325 * & 0.023 \\
\hline R11 & 2.721 & 1.054 & & & & & & & & & & & & & & $-0.375^{* *}$ & 0.321 * & -0.154 & 0.248 \\
\hline R12 & 2.907 & 0.971 & & & & & & & & & & & & & & & -0.085 & 0.203 & 0.090 \\
\hline R13 & 2.116 & 0.731 & & & & & & & & & & & & & & & & -0.001 & -0.029 \\
\hline R14 & 2.605 & 1.137 & & & & & & & & & & & & & & & & & 0.007 \\
\hline R15 & 2.372 & 0.952 & & & & & & & & & & & & & & & & & \\
\hline
\end{tabular}

${ }^{* *}=$ significant $5 \% ;{ }^{*}=$ significant $10 \%$. Sales figures $(\mathrm{SAL})$, production results $(\mathrm{PRO})$, and assets (ASS). 


\section{Appendix C}

Table A2. Saaty's average matrix for all respondents.

\begin{tabular}{|c|c|c|c|c|c|c|c|c|c|c|c|c|c|c|c|}
\hline & R1 & R2 & R3 & R4 & R5 & R6 & R7 & R8 & R9 & R10 & R11 & R12 & R13 & R14 & R15 \\
\hline R1 & 1.00 & 0.21 & 0.23 & 0.28 & 0.52 & 0.50 & 0.44 & 0.44 & 0.84 & 0.23 & 0.66 & 1.47 & 0.39 & 0.39 & 0.39 \\
\hline $\mathrm{R} 2$ & 6.21 & 1.00 & 1.80 & 1.80 & 3.80 & 1.00 & 1.00 & 3.40 & 1.40 & 2.20 & 3.40 & 3.40 & 5.00 & 3.00 & 3.00 \\
\hline R3 & 5.85 & 0.60 & 1.00 & 1.40 & 0.97 & 0.52 & 0.44 & 0.57 & 0.60 & 0.55 & 0.60 & 0.87 & 0.46 & 0.60 & 0.60 \\
\hline R5 & 3.40 & 0.50 & 2.08 & 3.81 & 1.00 & 1.67 & 1.27 & 2.20 & 3.80 & 2.87 & 3.80 & 2.60 & 3.80 & 4.60 & 2.60 \\
\hline R6 & 5.04 & 1.00 & 3.40 & 4.20 & 1.14 & 1.00 & 1.67 & 4.20 & 3.40 & 4.60 & 2.60 & 2.60 & 3.40 & 4.60 & 3.80 \\
\hline R7 & 2.60 & 1.00 & 2.62 & 4.61 & 1.27 & 1.14 & 1.00 & 2.60 & 3.00 & 2.60 & 1.00 & 1.00 & 1.00 & 1.00 & 1.80 \\
\hline R8 & 2.62 & 0.31 & 2.60 & 1.80 & 0.60 & 0.25 & 0.47 & 1.00 & 0.28 & 0.28 & 1.64 & 2.60 & 1.00 & 1.00 & 1.00 \\
\hline R10 & 4.21 & 0.60 & 3.40 & 1.00 & 0.85 & 0.25 & 0.60 & 3.42 & 1.68 & 1.00 & 1.80 & 1.00 & 1.40 & 1.00 & 1.00 \\
\hline R11 & 2.52 & 0.31 & 2.22 & 1.00 & 0.25 & 0.47 & 1.00 & 0.73 & 1.00 & 0.73 & 1.00 & 1.80 & 2.20 & 1.40 & 1.40 \\
\hline R12 & 0.70 & 0.41 & 1.00 & 2.22 & 0.47 & 0.47 & 1.00 & 0.57 & 1.81 & 1.00 & 0.87 & 1.00 & 2.60 & 2.20 & 1.80 \\
\hline R13 & 4.61 & 0.20 & 2.62 & 1.00 & 0.39 & 0.41 & 1.00 & 1.00 & 3.82 & 0.87 & 0.73 & 0.47 & 1.00 & 1.40 & 1.80 \\
\hline R14 & 4.61 & 0.41 & 2.22 & 1.00 & 0.36 & 0.39 & 1.00 & 1.00 & 3.42 & 1.00 & 1.00 & 0.47 & 0.87 & 1.00 & 1.80 \\
\hline R15 & 4.61 & 0.41 & 2.22 & 1.00 & 0.47 & 0.39 & 0.73 & 1.00 & 3.82 & 1.00 & 1.00 & 0.60 & 0.73 & 0.73 & 1.00 \\
\hline
\end{tabular}




\section{References}

1. Seuring, S.; Mülle, M. From a literature review to a conceptual framework for sustainable supply chain management. J. Clean. Prod. 2008, 16, 1699-1710. [CrossRef]

2. Dües, C.M.; Tan, K.H.; Lim, M. Green as the new Lean: How to use Lean practices as a catalyst to greening your supply chain. J. Clean. Prod. 2013, 40, 93-100. [CrossRef]

3. Marshall, D.; McCarthy, L.; Heavey, C.; McGrath, P. Environmental and social supply chain management sustainability practices: Construct development and measurement. Prod. Plan. Control 2015, 26, 673-690. [CrossRef]

4. Sharma, V.K.; Chandna, P.; Bhardwaj, A. Green supply chain management related performance indicators in agro industry: A review. J. Clean. Prod. 2017, 141, 1194-1208. [CrossRef]

5. Ciccullo, F.; Pero, M.; Caridi, M.; Gosling, J.; Purvis, L. Integrating the environmental and social sustainability pillars into the lean and agile supply chain management paradigms: A literature review and future research directions. J. Clean. Prod. 2018, 172, 2336-2350. [CrossRef]

6. Fischer, C.; Hartmann, M.; Reynolds, N.; Leat, P.; Revoredo-Giha, C.; Henchion, M.; Albisu, L.M.; Gracia, A. Factors influencing contractual choice and sustainable relationships in European agri-food supply chains. Eur. Rev. Agric. Econ. 2010, 36, 541-569. [CrossRef]

7. Pérez-Mesa, J.C.; Galdeano-Gómez, E. Collaborative firms managing perishable products in a complex supply network: An empirical analysis of performance. Supply Chain Manag. Int. J. 2015, 20, 128-138. [CrossRef]

8. Camanzi, L.; Malorgio, G.; García-Azcárate, T. The role of producer organizations in supply concentration and marketing: A comparison between European countries in the fruit and vegetable sector. J. Food Prod. Mark. 2011, 17, 327-354. [CrossRef]

9. Arzu, G.; Erman, T. Supply chain performance measurement: A literature review. Int. J. Prod. Res. 2010, 48, 5137-5155. [CrossRef]

10. Dobson, P.; Waterson, M.; Davies, S. The patterns and implications of increasing concentration in European food retailing. J. Agric. Econ. 2003, 54, 111-125. [CrossRef]

11. Galdeano-Gómez, E.; Pérez-Mesa, J.C.; Aznar-Sánchez, J. Internationalisation of SMEs and simultaneous strategies of cooperation and competition: An exploratory analysis. J. Bus. Econ. Manag. 2017, 17, 1114-1132. [CrossRef]

12. Singh, U.S.; Mishra, U.S. Supply Chain Management through Vertical Coordination in Vegetable Industry. Int. J. Supply Chain Manag. 2014, 3, 148-154.

13. Jiménez-Guerrero, J.F.; Pérez-Mesa, J.C.; De Burgos, J.; Piedra-Muñoz, L. Considering the consumer in the design of a supply chain of perishables. Int. Food Agribus. Manag. Rev. 2018, 21, 525-542. [CrossRef]

14. Hingley, M. Power imbalance in UK agri-food supply channels: Learning to live with the supermarkets? J. Mark. Manag. 2005, 21, 63-88. [CrossRef]

15. Flynn, B.B.; Huo, B.; Zhao, X. The impact of supply chain integration on performance: A contingency and configuration approach. J. Oper. Manag. 2010, 28, 58-71. [CrossRef]

16. Brandenburger, A.M.; Nalebuff, B.J. Co-opetition; Doubleday: New York, NY, USA, 1996.

17. Wassermann, S.; Faust, K. Social Network Analysis: Methods and Applications; Cambridge University Press: Cambridge, UK, 1994.

18. Hernández-Rubio, J.; Pérez-Mesa, J.C.; Piedra-Muñoz, L.; Galdeano-Gómez, E. Determinants of food safety level in fruit and vegetable wholesalers' supply chain: Evidences from Spain and France. Int. J. Environ. Res. Public Health 2018, 15, 2246. [CrossRef]

19. De Pablo, J.; Lévy, J.P.; Pérez-Mesa, J.C. Notes About the Production and Supply-Demand of Fruit and Vegetables in the Countries of the European Union. J. Food Prod. Mark. 2007, 13, 95-112. [CrossRef]

20. Fischer, C.; Hartman, M. Agri-Food Chain Relationships; CAB International: London, UK, 2010.

21. Kumar, R.; Singh, R.K.; Shankar, R. Strategy development by Indian SMEs for improving coordination in supply chain an empirical study. Compet. Rev. 2014, 24, 414-432.

22. Siddh, M.M.; Soni, G.; Jain, R.; Sharma, M.K.; Yadav, V. Agri-fresh food supply chain quality (AFSCQ): A literature review. Ind. Manag. Data Syst. 2017, 117, 2015-2044. [CrossRef] 
23. Matopoulos, A.; Vlachopoulou, M.; Manthou, V.; Manos, B. A conceptual framework for supply chain collaboration: Empirical evidence from the agri-food industry. Supply Chain Manag. Int. J. 2007, 12, 177-186. [CrossRef]

24. Manzini, R.; Accorsi, R.; Ayyad, Z.; Bendini, A.; Bortolini, M.; Gamberi, M.; Valli, E.; Toschi, T.G. Sustainability and quality in the food supply chain. A case study of shipment of edible oils. Br. Food J. 2014, 116, 2069-2090. [CrossRef]

25. Badole, C.M.; Jain, D.R.; Rathore, D.A.; Nepal, D.B. Research and Opportunities in Supply Chain Modeling: A Review. Int. J. Supply Chain Manag. 2013, 1, 63-85.

26. Yu, M.; Nagurney, A. Competitive food supply chain networks with application to fresh produce. Eur. J. Oper. Res. 2012, 224, 273-282. [CrossRef]

27. Blackburn, J.; Scudder, G. Supply Chain Strategies for Perishable Products: The Case of Fresh Produce. Prod. Oper. Manag. 2009, 18, 129-137. [CrossRef]

28. Smith, D.; Sparks, L. Temperature controlled supply chains. In Food Supply Chain Management; Bourlakis, M.A., Weightman, P.W.H., Eds.; Blackwell Publishing: Oxford, UK, 2004; pp. 179-198.

29. Gharehgozli, A.; Iakovou, E.; Chang, Y.; Swaney, R. Trends in global E-food supply chain and implications for transport: Literature review and research directions. Res. Transp. Bus. Manag. 2017, 25, 2-14. [CrossRef]

30. Gosling, J.; Purvis, L.; Naim, M.M. Supply chain flexibility as a determinant of supplier selection. Int. J. Prod. Econ. 2010, 128, 11-21. [CrossRef]

31. Pérez-Mesa, J.C.; Galdeano-Gómez, E.; Salinas, J. Logistics network and externalities for short sea transport: An analysis of horticultural exports from southeast Spain. Transp. Policy 2012, 24, 188-198. [CrossRef]

32. Gold, S.; Kunz, N.; Reiner, G. Sustainable Global Agrifood Supply Chains. Exploring the Barriers. J. Ind. Ecol. 2016, 21, 249-260. [CrossRef]

33. Iakovou, E.; Vlachos, D.; Achillas, C.; Anastasiadis, F. Design of sustainable supply chains for the agrifood sector: A holistic research framework. Agric. Eng. Int. CIGR J. 2014, 1-10.

34. Saura, J.R.; Palos-Sanchez, P.R.; Correia, M.B. Digital Marketing Strategies Based on the E-Business Model: Literature Review and Future Directions. In Organizational Transformation and Managing Innovation in the Fourth Industrial Revolution; IGI Global: Hershey, PA, USA, 2019; pp. 86-103.

35. Sini, P. Long and short supply chain coexistence in the agricultural food market on different scales: Oligopolies, local economies and the degree of liberalisation of the global market. Eur. Sci. J. 2014, 10, 1857-7881.

36. Tregear, A. Progressing knowledge in alternative and local food networks: Critical reflections and a research agenda. J. Rural Stud. 2011, 27, 419-430. [CrossRef]

37. Kneafsey, M.; Venn, L.; Schmutz, U.; Balázs, B.; Trenchard, L.; Eyden-Wood, T.; Bos, E.; Sutton, G.; Blackett, M. Short Food Supply Chains and Local Food Systems in the EU. A State of Play of their Socio-Economic Characteristics; Joint Research Centre Institute for Prospective Technological Studies; European Commission: Brussels, Belgium, 2013.

38. Marsden, T.; Banks, J.; Bristow, G. Food Supply Chain Approaches: Exploring their Role in Rural Development. Sociol. Rural. 2000, 40, 424-438. [CrossRef]

39. Siddh, M.M.; Soni, G.; Jain, R. Perishable food supply chain quality (PFSCQ): A structured review and implications for future research. J. Adv. Manag. Res. 2018, 12, 292-313. [CrossRef]

40. Mellat-Parast, M. Supply chain quality management. Int. J. Qual. Reliab. Manag. 2013, 30, 511-529. [CrossRef]

41. Borodin, V.; Bourtembourg, J.; Hnaien, F.; Labadie, N. Handling uncertainty in agricultural supply chain management: A state of the art. Eur. J. Oper. Res. 2016, 254, 348-359. [CrossRef]

42. Tsolakis, N.K.; Keramydas, C.A.; Toka, A.K.; Aidonis, D.A.; Iakovou, E.T. Agrifood supply chain management: A comprehensive hierarchical decision-making framework and a critical taxonomy. Biosyst. Eng. 2014, 120, 47-64. [CrossRef]

43. Ahumada, O.; Villalobos, J.R. Application of planning models in the agri-food supply chain: A review. Eur. J. Oper. Res. 2009, 195, 1-20. [CrossRef]

44. Rong, A.; Akkerman, R.; Grunow, M. An optimization approach for managing fresh food quality throughout the supply chain. Int. J. Prod. Econ. 2011, 131, 421-429. [CrossRef]

45. Boudahri, F.; Bennekrouf, M.; Sari, Z. Optimization and design of the transportation network of agri-foods supply chain: Application chicken meat. Int. J. Adv. Eng. Sci. Technol. 2011, 11, 213-220. [CrossRef]

46. Hobbs, J.E.; Young, L. Vertical linkages in Agri-Food Supply Chains in Canada and the United States; Research and Analysis Directorate Strategic Policy Branch Agriculture and Agri-Food Canada: Ottawa, Canada, 2001. 
47. Higgins, A.; Antony, G.; Sandell, G.; Davies, I.; Prestwidge, D.; Andrew, B. A framework for integrating a complex harvesting and transport system for sugar production. Agric. Syst. 2004, 82, 99-115. [CrossRef]

48. Widodo, K.H.; Nagasawa, H.; Morizawa, K.; Ota, M. A periodical flowering-harvesting model for delivering agricultural fresh products. Eur. J. Oper. Res. 2006, 170, 24-43. [CrossRef]

49. Salin, V. Information technology in agri-food supply chains. Int. Food Agribus. Manag. Rev. 1998, 1, 326-334. [CrossRef]

50. van der Vorst, J.G.A.J. Product traceability in food-supply chains. Accredit. Qual. Assur. 2006, 11, 33-37. [CrossRef]

51. Siddh, M.M.; Soni, G.; Jain, R.; Sharma, M.K. Structural model of perishable food supply chain quality (PFSCQ) to improve sustainable organizational performance. Benchmarking Int. J. 2018, 25, 2272-2317. [CrossRef]

52. Rajeev, A.; Pati, R.K.; Padhi, S.S.; Govindan, K. Evolution of sustainability in supply chain management: A literature review. J. Clean. Prod. 2017, 162, 299-314. [CrossRef]

53. Epperson, J.E.; Estes, E.A. Fruit and vegetable supply-chain management, innovations, and competitiveness: Cooperative Regional Research Project S-222. J. Food Distrib. 1999, 30, 38-43.

54. Hobbs, J.E.; Young, L. Closer vertical co-ordination in agrifood supply chains: A conceptual framework and some preliminary evidence. Supply Chain Manag. Int. J. 2000, 5, 131-142. [CrossRef]

55. Lusiantoro, L.; Yates, N.; Mena, C.; Varga, L. A refined framework of information sharing in perishable product supply chains. Int. J. Phys. Distrib. Logist. Manag. 2018, 48, 254-283.

56. Palos-Sanchez, P.; Martin-Velicia, F.; Saura, J.R. Complexity in the Acceptance of Sustainable Search Engines on the Internet: An Analysis of Unobserved Heterogeneity with FIMIX-PLS. Complexity 2018, 1-19. [CrossRef]

57. Stalk, G.; Hout, T.M. Competing Against Time: How Time-Based Competition Is Reshaping Global Markets; Free Press: New York, NY, USA, 1990.

58. Galdeano-Gómez, E.; Céspedes-Lorente, J.; Martínez-del-Río, J. Environmental performance and spillover effects on productivity: Evidence from horticultural firms. J. Environ. Manag. 2008, 88, 1552-1561. [CrossRef]

59. Deloitte. Global Powers of Retailing 2016: Navigating the New Digital Divide. Available online: https://www2.deloitte.com/content/dam/Deloitte/global/Documents/Consumer-Business/gx-cbglobal-powers-of-retailing-2016.pdf (accessed on 22 June 2017).

60. Serrano, M.; Pérez-Mesa, J.C.; Sánchez-Fernández, R. Product-country image and crises in the Spanish horticultural sector: Classification and impact on the market. Econ. Agrar. Recur. Nat. 2018, 18, 111-133.

61. Pérez-Mesa, J.C.; Serrano, M.; Sánchez-Fernández, R. Measuring the impact of crises in the horticultural sector: The case of Spain. Br. Food J. 2019, 121, 1050-1063. [CrossRef]

62. Brennen, B.S. Qualitative Research Methods for Media Studies; Routledge: New York, NY, USA, 2012.

63. Jensen, K.B. The social origins and uses of media and communication research. In A Handbook of Media and Communication Research: Qualitative and Quantitative Methodologies, 2nd ed.; Jensen, K.B., Ed.; Routledge: London, UK, 2012; pp. 273-293.

64. Saaty, T.L. Decision making with the analytic hierarchy process. Int. J. Serv. Sci. 2008, 1, 83-98. [CrossRef]

65. Saaty, T.L. Fundamentals of Decision Making and Priority Theory with the Analytic Hierarchy Process; RWS Publications: Pittsburg, CA, USA, 2000.

66. Fichtner, J. On deriving priority vectors from matrices of pairwise comparisons. Socio-Econ. Plan. Sci. 1986, 20, 341-345. [CrossRef]

67. Easley, R.; Valacich, J.; Venkataramanan, M. Capturing group preferences in a multicriteria decision. Eur. J. Oper. Res. 2000, 125, 73-83. [CrossRef]

68. Forman, E.; Peniwati, K. Aggregating individual judgments and priorities with the Analytic Hierarchy Process. Eur. J. Oper. Res. 1998, 108, 165-169. [CrossRef]

69. Chan, S.H.; Kensinger, J.W.; Keown, A.J.; Martin, J.D. Do strategic alliances create value? J. Financ. Econ. 1997, 46, 199-221. [CrossRef]

70. Van Beers, C.; Van der Panne, G. Geography, knowledge spillovers and small firms' exports: An empirical examination for The Netherlands. Small Bus. Econ. 2011, 37, 325-339. [CrossRef]

71. Petersen, K.; Handfield, R.; Ragatz, G. Supplier integration into new product development: Coordinating product, process, and supply chain design. J. Oper. Manag. 2005, 23, 371-388. [CrossRef]

72. Calof, J.L. The Relationship between Firm Size and Export Behavior Revisited. J. Int. Bus. Stud. 1994, 25, 367-387. [CrossRef] 
73. Piedra-Muñoz, L.; Galdeano-Gómez, E.; Pérez-Mesa, J.C. Is Sustainability Compatible with Profitability? An Empirical Analysis on Family Farming Activity. Sustainability 2016, 8, 893. [CrossRef]

74. Egea, F.; Torrente, R.; Aguilar, A. An efficient agro-industrial complex in Almería (Spain): Towards an integrated and sustainable bioeconomy model. New Biotechnol. 2017, 40, 103-112. [CrossRef] [PubMed]

75. Giagnocavo, C.; Galdeano-Gómez, E.; Pérez-Mesa, J.C. Cooperative Longevity and Sustainable Development in a Family Farming System. Sustainability 2018, 10, 2198. [CrossRef]

(c)

(C) 2019 by the authors. Licensee MDPI, Basel, Switzerland. This article is an open access article distributed under the terms and conditions of the Creative Commons Attribution (CC BY) license (http://creativecommons.org/licenses/by/4.0/). 